
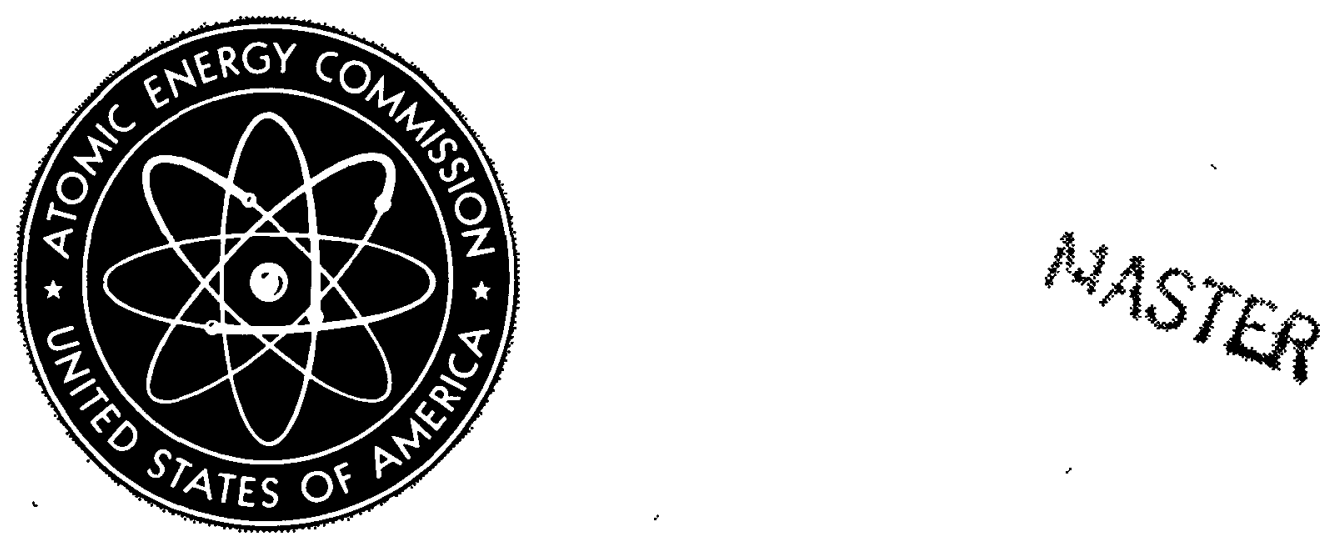

GEAP-3961

LEGAL NOTICE

The report was prepared as an account of Government eponsored work Nelther the Unitod States nor the Commisetion nor any perbon acting on behalf of the Commiselon

A Makes any warranty or representation expressod or impiled with respect to the accu racy completeness or usefulness of the tnformalion contained in this roport or that the use
of any informstion apparatus method or procoss dieclosed in this report may not infringe of any information apparatus
privately owned rights or

B Aasumes any liabluties with respect to the use of or for dengen resulting from the

Abeing any lisblitses with respect to the ube of or for damagen resulting from the

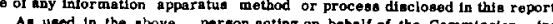

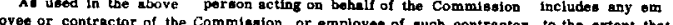
auch employee or contractor of the Commisston or employee of unch cast-actor praperas disteminates or provides access to any information puranant to hle employment or contrest with the Commission or his employment with such contractor

\title{
PREDICTION OF THE CRITICAL HEAT FLUX IN FORCED CONVECTION FLOW
}

By

S. Levy

June 20,1962

Atomic Power Equipment Department General Electric Company San Jose, California 


\section{DISCLAIMER}

This report was prepared as an account of work sponsored by an agency of the United States Government. Neither the United States Government nor any agency Thereof, nor any of their employees, makes any warranty, express or implied, or assumes any legal liability or responsibility for the accuracy, completeness, or usefulness of any information, apparatus, product, or process disclosed, or represents that its use would not infringe privately owned rights. Reference herein to any specific commercial product, process, or service by trade name, trademark, manufacturer, or otherwise does not necessarily constitute or imply its endorsement, recommendation, or favoring by the United States Government or any agency thereof. The views and opinions of authors expressed herein do not necessarily state or reflect those of the United States Government or any agency thereof. 


\section{DISCLAIMER}

Portions of this document may be illegible in electronic image products. Images are produced from the best available original document. 


\section{LEGAL NOT ICE}

This report was prepared as an account of Government sponsored work. Neither the United States, nor the Commission, nor any person acting on behalf of the Commission:

A. Makes any warranty or representation, expressed or implied, with respect to the accuracy, completeness, or usefulness of the information contained in this report, or that the use of any information, apparatus, method, or process disclosed in this report may not infringe privately owned rights; or

B. Assumes any liabilities with respect to the use of, or for damages resulting from the use of any information, apparatus, method, or process disclosed in this report.

As used in the above, "person acting on behalf of the Commission" includes any employee or contractor of the Commission, or employee of such contractor, to the extent that such employee or contractor of the Commission, or employee of such contractor prepares, disseminates, or provides access to, any information pursuant to his employment or contract with the Commission, or his employment with such contractor.

This report has been reproduced directly from the best avallable copy.

Printed in USA. Price $\$ 0.75$. Available from the Office of Technical Services, Department of Commerce, Washington 25, D. C. 


\section{PREDICTION OF THE CRITICAL HEAT FLUX \\ IN FORCED CONVECTION FLOW}

By

S. Levy

$$
\text { June 20, } 1962
$$

Prepared Under

USAEC Contract AT(04-3)-189, P.A. No. 11

\section{ATOMIC POWER EQUIPMENT DEPARTMENT \\ GENERAL ELECTRIC \\ SAN JOSE, CALIFORNIA}


-

4

. 
Page No.

SUMMARY

1

INTRODUCTION

1

Description of the Method

1

Critical Heat Flux in Subcooled Forced Convection

2

Pool Boiling

2

Subcooled Pool Bolling

2

Subcooled Forced Convection

3

Critical Heat Flux in Forced Convection with Net Vapor Generation

5

REFERENCES

11 
FIgure 1 - COMPARISON OF PREDICTION WITH SUBCOOLED WATER DATA AT 2000 PSIA

Figure 2 - POSSIBILITY OF HYDRAULIC OSCILLATIONS AT LOW FLOWS

Figure 3 - COMPARISON OF PREDICTION WITH SUBCOOLED WATER DATA AT PRESSURE OF 60-2750 PSIA

Figure 4 - COMPARISON OF PREDICTION WITH SUBCOOLED WATER DATA IN ANNULUS AT 1000 PSIA

Figure 5 - EFFECTS OF SUBCOOLING AND FORCED CONVECTION UPON CRITICAL HEAT FLUX OF WATER

Figure 6 - COMPARISON OF PREDICTION WITH CRITICAL HEAT FLUX DATA IN RECTANGULAR CHANNELS AT 2000 PSIA

Figure 7 - COMPARISON OF PREDICTION WITH OTHER CRITICAL HEAT FLUX DATA AT 2000 PSIA

Flgure 8 - TYPICAL SCATTER IN EXPERIMENTAL DATA AT 2000 PSIA

Figure 9 - COMPARISON OF PREDICTION WITH CISE DATA AT 1000 PSIA

Figure 10 - COMPARISON OF PREDICTION WITH RECTANGULAR CHANNEL DATA AT 1000 PSIA

Figure 11 - COMPARISON OF PREDICTION WITH CISE DATA AT OTHER PRESSURES

Flgure 12 - VALUE OF PARAMETER $\frac{\mathrm{BC} \rho}{\mu_{L}}$ FOR FLOW BETWEEN PARALLEL PLATES

F1gure 13 - EFFECTS OF ASSYMETRIC HEATING UPON DENSITY DISTRIBUTION

Figure 14 - COMPARISON OF PREDICTION WITH INTERNALLY HEATED ANNULAR DATA AT 1000 PSIA

\section{LIST OF TABLES}

Table I

STEAM QUALITY, $\mathbf{x}$

$\frac{\text { Page No. }}{9}$ 
PREDICTION OF THE CRITICAL HEAT FLUX

IN FORCED CONVECTION FLOW

\section{SUMMARY}

A superposition model is developed to predict the critical heat flux in forced convection flow. The model is applied to available experimental results in boiling water flows and good agreement is obtained between the model and test data over the multitude of geometries, flow rates, pressures, and fluid enthalpies tested to-date.

\section{INTRODUCTION}

Most predictions of the critical heat flux in forced convection flow have been empirical. A multitude of correlations have been proposed in the literature and typical examples are given in references (1), (2), and (3). By contrast, the number of analytical studies has been very limited. Only four models have been presented to-date, all of them published in recent years.

The earliest attempt to obtain an analytical solution in flowing systems was made by Griffith $(4)$ in 1958. Griffith postulated that the critical heat flux occurred when steam bubbles covered a certain fraction of the heater surface. Using dimensional analysis, he was able to specify this fraction in terms of flow rate, subcooling, and fluid properties. In 1959, Isbin, Vanderwater, Fauske, and Singh(5) proposed an annular flow model consisting of a liquid film flowing along the channel walls and a central core of steam and dispersed water droplets. It was assumed that liquid was lost from the film by evaporation and entrainment and replenished by diffusion from the central core. Critical heat flux conditions were taken to correspond to disappearance of the liquid film. In 1960, Goldmann, Firstenberg, and Lombardi (6) utilized the similarity between the mass transfer coefficient and friction factor to calculate the critical heat flux. Droplet diffusion through a steam boundary layer was taken as the dominant mechanism in this analysis. In 1962, Tippets $(7)$ presented the most comprehensjue model yet developed. Starting from the flow model of Isbin and his co-workers $(5)$, he was able to obtain analytical expressions for the liquid film thickness from stability considerations and to determine the liquid diffusion rates from the central core by means of a turbulent mixing length model.

It is the purpose of this report to present another analytical solution to the problem of critical heat flux in forced convection flow. The proposed model utilizes a superposition method to predict the critical heat flux over the entire range of available test results. It covers both flowing and non-flowing systems under subcooled and net vapor generation conditions.

\section{Description of the Method}

The superposition method consists of subdividing a complex heat transfer problem into subproblems more amenable to analysis. Solutions are derived for the subproblems and these are added algebraically to obtain an analytical representation 
of the overall process. This simplified approach is the basis of predictions proposed here for the critical heat flux in forced convection flow with subcooled fluid and net vapor generation.

In the case of subcooled flow, the critical heat flux under non-flow or pool bolling conditions is first specified. To this heat transfer rate are next added the heat conducted from the surface by the subcooled non-flowing fluid and the heat convected from it by the subcooled flowing fluid. Simllarly, in the case of net vapor generation, heat convected from the surface is first added to the pool boiling critical heat flux and an equivalent mass transfer rate is next subtracted from it to account for the presence of vapor in the stream.

Analytical expressions for both cases are derlved in the next two sections. It is, however, important before proceeding with the analysis to realize that

1. superposition methods are approximate because they neglect the interaction of the constituent solutions upon one another; and

2. the method of superpgsition is not new to the boiling field. It has been used previously by Rohsenow $(8)$ to predict the effects of forced convection in nucleate boiling peat transfer. More recently, it has been applied by Zuber, Tribus, and Westwater $(9)$ to determine the critical heat flux in subcooled pool boiling.

\section{Critical Heat Flux in Subcooled Forced Convection}

As previously indicated, the analysis is carried out in three steps. Addition of the solutions at each step gives the critical heat flux in pool boiling, subcooled pool boiling, and subcooled forced convection flow.

Pool Boiling

Correlations for the critical heqt flux in pool boiling have been proposed by Kutateladze (10) and Borishanski (II). A similar relation was recently derived in reference (9) on theoretical grounds. Zuber, Tribus, and Westwater postulated that the critical heat flux occurred when the countercurrent flow of liquid and vapor at the heater surface became hydrodynamically unstable. Analysis of this unstable condition gave the following equation for the critical heat flux

$$
\left(\frac{q}{A}\right)_{p}=0.131 h_{f g} \rho_{v}\left[\frac{\sigma q^{2}\left(\rho_{L}-\rho_{v}\right)}{p_{v}^{2}}\right]^{1 / 4}
$$

Equation (1) has been checked against available experimental data and has been found to agree well with the test results.

subcooled Pool Boiling

The critical heat flux in subcooled non-flowing systems was derived in reference (9). A heat conduction term was added to Equation (1) to account for the intermittent contact of subcooled fluid and heater surface. The conduction term is 
given by

$$
\left(\frac{9}{A}\right)_{c}=0.696 \sqrt{k_{L} \rho_{L} C_{P_{L}}} \quad\left(\frac{\rho_{L}-\rho_{v}}{\sigma}\right)^{1 / 4}\left[\frac{\sigma g^{2}\left(\rho_{L}-\rho_{v}\right)}{\rho_{v}^{2}}\right]^{1 / 8} \Delta T_{\text {sub }}
$$

Addition of Equations (1) and (2) gives the critical heat flux for subcooled pool boiling and, as shown, in reference (9) good agreement is obtained between the sum of Equations (1) and (2) and the test results of Kutateladze and schneidermann(12).

Subcooled Forced Convection

The critical heat flux in this case is obtained by adding a convection term to the sum of Equations (1) and (2). The forced convection term is equal to

$$
\left(\frac{q}{A}\right)_{F}=h_{L}\left(T_{w}-T_{s}\right)+h_{L} \Delta T_{\text {sub }}
$$

The liquid heat transfer coefficient $h_{L}$ in Equation (3) is calculated from a colburn type relation

$$
h_{L}=0.023 \frac{k_{L}}{D}\left(\frac{G D}{\mu_{L}}\right)^{0.8}\left(\frac{\mu c_{p}}{k}\right)_{L}^{0.33}
$$

The temperature difference (TW-Ts) can be computeg from one of the many nucleate bolling correlations available in the literature $(8),(13),(14)$. In the case of water, the simplified Jens-Lottes $(1)$ equation is recommended*

$$
T_{w}-T_{s}=\frac{60}{e^{9 / 900}}\left(\frac{9}{A} \frac{1}{10^{6}}\right)^{1 / 4}
$$

where q/A is the critical heat flux obtained by adding Equations (1), (2), and (3).

Critical heat flux values for forced convection flow of water were calculated from the sum of Equations (1), (2), and (3) and were compared to avallable test results. The predictions are based upon the use of Eauations (4) and (5) with water properties evaluated at saturated conditions for simplification purposes. The ratio of predicted to measured critical heat flux at 2000 psia is plotted in piguse 1 for the test conditions reported in reference (2). It is seen from this figure that over 85 percent of the test points are correlated within $\neq 30$ percent. A definite trend, with respect to mass-flow rates, is also noticeable. The experimental results tend to fall below the predictions at low flow rates and above them at very high flow rates.

\footnotetext{
*Equation (5) requires the use of a trial and error method. The contribution of the term (Tw-Ts) is usually small and a first approximation can be obtained by neglecting it.
} 
This deviation from the superposition model can be explained.

At reduced flow rates, the measured values of critical heat flux are probably low due to hydraulic oscillations. This possibility is illustrated in Figure 2 where experimental data shown in Figure 1 and obtained at two relatively constant flow rates are plotted. The curves in Figure 2 exhlbit characteristics noted in reference (15) when the test loop was hydrodynamically unstable. In the high flow range, the low values predicted by the analysis are attributed to the fact that it underpredicts the effects of forced convection. The forced convection term becomes particularly important at high flows and the values derived from Equation (4) are low because they neglect the presence of vapor in the stream. Vapor exists in the stream even at subcooled conditions and its presence will tend to accelerate the fluid in the channel*. The effects of subcooled vapor fraction are also expected to be important for small channel spacings since the vapor fraction in a subcooled fluld increases with reduced channel size $(16),(17)$.

Additional comparisons of the proposed model to test results are shown in Figures 3 and 4. Fygure 3 covers experimental results obtained at pressures other than 2000 psia (2), (18), while Figure 4 covers data measured in an annulus at 1000 psia (19). Again, correlation of more than 85 percent of the test points within 30 percent is noted in Figure 3, while in Figure 4, all the test data fall within this range. Figure 4 also exhlbits an interesting reverse trend with flow rate. Because the results in Figure 4 were obtained with an annulus heated only on the inside surface, channeling of cold water on the unheated surface must take place. This channeling is expected to increase with increased flow rates and the predicted values should exceed the measurements in this range.

Bxamination of Figures 1, 3, and 4 reveals that the superposition method gives a satisfactory prediction of the critical heat flux of water in forced convection flow. The comparison is all the more satisfying when it is realized that test points often exhibit a 30 percent experimental spread. Further verification of the superposition model by applying it to other fluids and conditions is not possible at the present time because insufficient test results are available. Some interesting qualitative trends can still be inferred from the proposed equation. The effects of subcooling and forced convection upon the critical heat flux of water at various pressures are 1llustrated in Figure 5. As shown in Figure 5, increased subcooling and flow tend to shift the peak critical heat flux to lower pressures. Simllarly, the sum of Equations (1), (2), and (3) gives an increase in the critical heat $f l u x$ as the hydraulic diameter is reduced. It finally makes it possible to evaluate the critical heat flux in fluids not previously tested. It 35ould be noted again that Equation (5) applies only to water and that for other fluids the wall superheat can be evaluated from equations given in references (8), (13), and (14). Equation (4) should also be appropriately modified if fluids of low Prandtl number are utilized.

*This increased velocity could be estimated from reference (17). However, once this Is done, one departs from the simple superposition model which allows no interaction betweer the constituent solutions. 
Critical Heat Flux in Forced Convection

With Net Vapor Generation

With net vapor generation, the solution starts again with the non-flowing saturated liquid. The saturated liquid is next set into motion, and finally vapor is added to the main stream. The critical heat flux in the case of a non-flowing saturated liquid was previously specified [see Equation (I)] while motion of the saturated liquid requires the addition of a convection term. The convection heat transfer is obtained from Equation (2), except that the second term on the right side of Equation (2) now drops out since the fluid is no longer subcooled. This leaves only the effects of vapor in the main stream to be evaluated. The presence of vapor in the stream can be represented by an equivalent mass transfer rate. The mass transfer rate is obtained from two-phase density distributions derived in reference (20). According to reference (20), the density of a two-phase flowing mixture starts as liquid at the channel wall and decreases towards the center of the channel. Associated with this density distribution is a mass transfer rate $M$ equal to

$$
M=-\left.C \frac{d \rho}{d y}\right|_{y=0}
$$

The term $C$ in Equation (6) is an equivalent diffusion ccefficient. The gradient $\mathrm{d} \rho / \mathrm{d} y$ can be calculuted from the mixing length solutions of reference (20) and Puation (6) vecomes

$$
M=\frac{c f_{L}}{\mu_{L}} \frac{k^{2} \beta^{2}}{1-\rho_{a} / \rho_{L}} G
$$

In Eauation (7) $\mathrm{K}$ is the constant used in the mixing length expression (usually taken as 0.4 ) while $\beta$ is a parameter dependent upon the channel geometry, the ratio of mean fluid to liquid density, and the liquid Reynolds number oused upon the total mass 1 low rate $G$.

Part of the mass transfer rate $M$ nust be in the vapor stage and the corresponding vapor flow $M_{M}$ is tiken proportional to the average vapor fraction $\bar{\alpha}$ in the chernel

$$
M_{v}=M \bar{\alpha}=\frac{C R}{\mu_{L}} \frac{k^{2} \beta^{2}}{1-p / \rho_{L}} G
$$

*A two-phase heat transfer convection term would be more appropriate here. Satisfactory correlations for two-phase flo: heat transter are not available and Equation (?) is utilized in the meantime. Note that in most practical applications, the convection term is small so that use of Equation (2) is acceptable. 
To produce this mass transfer rate it would be necessary to have a heat flux (1) equal to

$$
\left(\frac{q}{A}\right)_{M}=-h_{f g} M_{v}=-h_{f g} \frac{c \rho_{L}}{\mu_{L}} \frac{k^{2} \beta^{2}}{1-R_{V / \rho_{L}}} G
$$

A negative sign is used in Equation (9) since the vapor mass transfer rate is towards the channel wall rather than away from it. Equation (9) can now be added to Equations (I) and (2) to obtain the desired solution. Before proceeding with this additon, a small modification will first be made to Equation(9). The heat flux rate of Equation (9) assumes that there exists an infinitely thin liquid f1lm against the channel wall. If the liquid film were actually finite, as reported in reference (7), the mass transfer rate will depend upon the ratio of liquid film thickness to channel spacing or diameter. The mass transfer rate would decrease as this ratio increases, tending to zero as the liquid film thickness approaches half of the channel spacing. This effect can be approximated by a power type expression, $(D / 2 \delta)^{m}$ where $\delta$ represents the liquid film thickness. If we assume that $\delta$ is proportional to the wave length at the interface of the liquid film and if the wave length is taken as the critical wave length obtained in the analysis of pool boiling, the expression for $\left(\frac{q}{A}\right)_{M}$ becomes

$$
\left(\frac{q}{A}\right)_{M}=-\frac{B C \rho_{L}}{\mu_{L}} h_{f g} \frac{K^{2} \beta^{2}}{1-f_{V / L}} \sigma\left[\frac{\left(\rho_{L}-\rho_{V}\right) D^{2}}{4 \pi \pi^{2} \sigma}\right]^{m / 2}
$$

where $B$ is a proportionality constant. 'ine exponent $m$ is specified on the basis that we are dealing with a hydrodynamically unstisble system. Stability analyses have shown $(7),(9)$, that the critical velocity (proportional here to Mv/ $f_{v}$ ) varies inversely with the square root of the wave length, and $\mathrm{m}=1 / 2$. The final expression for $\left(\frac{q}{A}\right)_{M}$ is

$$
\left(\frac{q}{A}\right)_{M}=-\frac{B C \rho_{L}}{\mu_{L}} h_{f g} \frac{k^{2} \beta^{2}}{1-\rho_{v / \rho_{L}}} G\left[\frac{\left(\rho_{L}-\rho_{v}\right) D^{2}}{4 \pi^{2} \sigma}\right]^{1 / 4}
$$

The surn of Equations (1), (2) and (11) gives the critical heat flux in forced convection flow with net vapor generation. By contrast to subcooled flow, the solution now includes an undefined term, $B C / L / \mu_{L}$ which must be obtained from experimental data. Before proceeding with calculation of the grouping $B C \rho_{L} / \mu_{L}$ let us qualitatively examine the trends predicted by the model. In order to facilitate the discussion, the dependence of the parameter $\beta$ on total liquid Reynolds number $60 / \mu_{L}$ will first be expressed analytically. In reference (20), values of $\beta$ are tabulated in terms ef $P / \beta_{L}$ and $60 / \mu_{L}$. For instance at a total liquid Reynolds number, $60 / \mu_{L}$, of $10^{5}$ the lollowing relation exists between $\beta$ and mean density in a circular pipe

$$
\begin{array}{lllllllll}
\beta & 0.04 & 0.1 & 0.2 & 0.3 & 0.4 & 0.5 & 0.6 & 0.7 \\
\beta / \beta_{L} & 0.730 & 0.477 & 0.253 & 0.141 & .0 .0836 & 0.0516 & 0.0335 & 0.0227
\end{array}
$$


The corresponding values for flow between parallel plates are

$$
\begin{array}{lllllllll}
\beta & 0.04 & 0.1 & 0.2 & 0.3 & 0.4 & 0.5 & 0.6 & 0.7 \\
\beta / \rho & 0.715 & 0.453 & 0.227 & 0.122 & 0.0678 & 0.0397 & 0.0245 & 0.0158
\end{array}
$$

Values at other Reynolds numbers are given in reference (20). It was, however, found that these could be readily predicted from the equation

$$
\beta=\beta^{\prime}\left(\frac{G D}{\mu_{L}} \frac{1}{10^{5}}\right)^{-1 / 6}
$$

where $\beta^{\prime}$ is the value of the parameter $\beta$ at $G D / \mu_{2}=10^{5}$. Also, plots of $\beta$ versus $\beta / \rho_{L}$ show that the circular pipe values of $\beta$ are about 8.3 percent larger then for parallel plates. Equation (11) can be rewritten

$$
\left(\frac{q}{A}\right)_{M}=-\frac{B C \rho_{L}}{\mu_{L}} l_{f g} \frac{K^{2} \beta^{2}}{1-\rho_{v / \rho_{L}}}\left[\frac{\left(\rho_{L}-\rho_{v}\right) D^{2}}{4 \pi^{2} \sigma}\right]^{1 / 4} \sigma\left(\frac{\sigma D}{\mu_{L}} \frac{1}{10^{5}}\right)^{-1 / 3}
$$

Fiffects of vapor fraction, flow rate, and geometry can now be evaluated from Equation (13). The most important results are as follows:

1. Increased vapor fraction reduces the mean fluid density. The only term affected in Equation (13) by this reduction is the parameter $\beta$. According to the preceding tabulations, $\beta$ increases rapidly as the ratio $\beta / \beta$ is reduced. In other terms $(\% / A) M$ becomes larger with increased vold fraction and the critical heat flux drops sharply. This is without doubt the dominant effect in Equation (13).

2. The heat flux $/ 9 / 4 / M$ is proportional to $G^{2} / 3$ according to Equation (13). Increased flow velocity means, therefore, a reduced value of critical heat flux. From a physical viewpoint, the trend can be explained if one realizes that an increased flow rate flattens the density profile and leads to higher density gradients at the wall.

3. There are compensating effects in the case of hydraulic diameter. According to Equation (13), the critical heat flux increases as the hydraulic dismeter is reduced but its dependence upon hydraulic diameter is small.

4. Since the values of $\beta^{\prime}$ are higher for a circular pipe than in a parallel plate geometry, the circular pipe will give slightly lower critical heat flux values than a parallel plate system.

All the above qualitative trends are in agreement with test results. A detailed comparison of the analysis and data will now be presented for the case of weter flow with net steam generation.

Figure 6 shows a comparison of the predictions with experimental results in an $0.097 \times 1$ inch rectangular channel at $2000 \mathrm{nsia}(2)$. The predictions are based upon a value of 0.355 for the grouping $B C \rho_{L} / \mu_{L} \cdot$ It is seen that over 85 percent of the 
test polnts are correlated within $t 30$ percent and that over 95 percent fall within \pm 40 percent. Experimental data obtained at Bettis in other channel sizes are shown in Figure 7. The same degree of correlation is obtained as in Figure 6. It can, therefore, be inferred from Figures 6 and 7 that the superposition model gives satisfactory answers over the large range of fluid enthalpy, flow rate, and channel geometries tested at $2000 \mathrm{psia}$. It is true that correlation of the data within a narrower band would be desirable. This, however, is rather difficult at the present tine since the test points exhibit an inherent scatter of at least the same range. Typlcal experimental data obtained in a fixed channel and at a relatively constant mass flow rate are plotted in Figure 8 . It is seen that for all three cases illustrated the spread in test points exceeds $\$ 30$ percent and sometimes reaches up to $\$ 60$ percent.

Additional comparisons of the model with test results are given in Figures 9, 10 , and 11 . Flgures 9 and 10 cover data obtained at 1000 psia, while Figure 11 deals with 600 and 1200 psia. A satisfactory correlation is obtained in Figure 9 with CISE data (21) at different flow rates, heated lengths and pipe diameters. Similarly, the data of Tippets are well correlated in Figure 10. Test results at 600 and $1000 \mathrm{psia}$ are also satisfactorily predicted in Figure 11 . It should be noted here that only test results with heated length to diameter ratio greater than 60 are considered in Flgures 6 to 11 . Also, CISE data with inlet steam quality above 0.15 were not used as they produced a peak in the curve of critical heat flux versus steam quality. * Also, only the test data obtained by Tippets with a 0.010 inch heater ribbon are show in Figure 10 because they are considered more reliable. Finally the following values of vold fraction versus steam quality were used: (see Table I).

The values of the parameter $B C / / / \mu_{L}$ used in Flgures 6 to 11 are shown in Figure 12 . A simple relation is obtained when this parameter is plotted against the density ratio $\mathrm{f} / \mathrm{P}_{\mathrm{V}}$. An approximate equation for $B C / L / \mu_{L}$ is

$$
\frac{B C \rho_{L}}{\mu_{L}}=2.75 \frac{\rho_{v}}{R_{L}}
$$

This relation is valid only for the two geometries treated in reference (20), namely, pipe and parallel plate llow. It is expected that the parallel plate model. can be applied to an annulus heated on both surfaces. In the speclal case of an annulus or parallel plate system heated on one side only, the previous analysis breaks down since the density distribution will no longer be symmetrical as assumed in reference (20). The effects of heating only one surface are schematically represented in Figure 13. A density distribution skewed towards the heated surface: :HII result and if the average steam density is maintained the same as in the case of heating both surfaces, the density gradient next to the heated wall will be much larger for assymetrical heating. Until solutions of the type derived in reference (20) are developed for assymetrical heating, a simplified approach for taking it into account consists of changing the value of the grouping $\mathrm{BC} / \mathrm{K}_{L}$

*This peak is probably due to flow osclllations as illustrated in Flgure 2.

* Another method is to assume that the heated surface sees 2 lower mean density than exists over the entire channel. 


\section{TABLE I}

STEAM QUALITY, $x$

\begin{tabular}{|ll|l|l|l|l|l|l|l|l|l|l|l|l|l|l|}
\hline & 0 & 0.010 & 0.050 & 0.100 & 0.200 & 0.300 & 0.400 & 0.500 & 0.600 & 0.700 & 0.800 & 0.900 & 1.00 & Pressure \\
Void Fraction & 0 & 0.250 & 0.561 & 0.617 & 0.785 & 0.830 & 0.865 & 0.894 & 0.917 & 0.939 & 0.960 & 0.982 & 1.000 & 600 \\
Void Fraction & 0 & 0.150 & 0.445 & 0.590 & 0.722 & 0.785 & 0.830 & 0.865 & 0.896 & 0.922 & 0.950 & 0.976 & 1.000 & 1000 \\
Void Fraction & 0 & 0.118 & 0.395 & 0.552 & 0.690 & 0.760 & 0.813 & 0.854 & 0.885 & 0.916 & 0.945 & 0.974 & 1.000 & 1200 \\
Void Fraction & 0 & 0.068 & 0.278 & 0.448 & 0.647 & 0.758 & 0.830 & 0.879 & 0.917 & 0.944 & 0.968 & 0.985 & 1.000 & 2000 \\
\hline
\end{tabular}


It was found that the experimental data of Janssen and Kervinen (19) at 1000 psia in an internally heated annulus could be predicted by multiplying the values in Figure 12 by 2.8 . Test results $\mathrm{given}$ in reference (19) indicate that the constant 2.8 remains relatively the same as the pressure is varied. A recommended equation for annuli or parallel plates heated on one side only is, therefore,

$$
\frac{B C \rho_{L}}{\mu_{L}}=7.7 \frac{\rho_{V}}{p_{L}}
$$

The use of Equations (13) and (15) is illustrated in Figure 14. Good correlation is obtained of the test results given in reference (19) at various flow rates, heated lengths and hydraulic diameters.

Figure 14 illustrates, once again, the ability of the superposition model to grasp the most important experimental trends. This ability has now been repeatedly demonstrated for forced convection flow of water under subcooled and net steam generation conditions. An important characteristic of the model is that it agrees with the results of so many experimenters. There are, without doubt, some regions where the proposed correlation could still be improved. Such improvements must, however, await the following:

1. The reduction in the spread of experimental points. Such spread was illustrated in Figure 8, but it can also be observed in Figures 9, 11, and 13.

2. Better understanding of the phenomena involved. The problem of diffusion in a two-phase mixture deserves further analytical and experimental attention.

3. Additional test results with fluids other than water to establish the validity of the proposed equations and in particular to verify the proposed variation of $B C / L / \mu_{L}$ with fluid properties. 
REFFERENCES

1. Jens, W.H., and P.A. Lottes, "Analysis of Heat Transfer, Burnout, Pressure Drop, and Density Data for High Pressure Water", ANL-4627, May 1951.

2. DeBortol1, R.A., et al, "Forced Convection Heat Transfer Burnout Studies for Water in Rectangular Channels and Round Tubes at Pressures Above 500 psia", WAPD-188, October 1958.

3. Janssen, E., and S. Levy, "Burnout Ifimit Curves for Boiling Water Reactors", APED 3892, April 1962.

4. Griffith, P., "The Correlation of Nucleate Boiling Burnout Data", ASME Paper 57-HT-2l, 1957.

5. Isbin, H.S., et al, "A Model for Correlating Two-Phase, Steam-Water, Burnout Heat Transfer Fluxes", Trans. ASME, C, 83, (2), May 1961.

6. Goldmann, K., Firstenberg, H. and C. Lombardi, "Burnout in Turbulent Flow A Droplet Diffusion Model", Trans. ASME, C, 83, (2), May 1961.

7. Tippets, F.E., "Critical Heat Flux and Flow Pattern Characteristics of High Pressure Bolling Water in Forced Convection", GEAP-3766, Apr11 1962.

8. Rohsenow, W.H., "A Method of Correlating Heat Transfer Data for Surface Bolling of Ifiquids", Trans. ASME, vol. 74, 1952.

9. Zuber, N., Tribus, M., and J.W. Westwater, "The Hydrodynamic Crisis in Pool Boiling of Saturated and Subcooled Iiquids", 1961 International Heat Transfer Conference, Boulder, Colo., Part II-A (27).

10. Kutateladze, S.S., "A Hydrodynamic Theory of Changes in a Boiling Process Under Free Convection", Izvestla Akademia Nauk Otdelenie Tekhnicheski Nauk, No. 4 1951.

11. Borishanski, V.M., "An Equation Generalizing Experimental Data on the Cessation of Bubble Bolling in a Large Volume of Liquid", Zhurmal Tekhnichesk1 Fiziki, Vol. 25, 1956.

12. Kutateladze, S.S. and L.L. Schneldermann, "Experimental Study of the Influence of the Temperature of a Iiquid on the Change of the Rate of Boiling", AEC translation 3405 .

13. Forster, K.E. and R. Grief, "Heat Transfer to a Boiling Liquid-Mechanism and Correlations", Trans. ASME, 81, C, 1959.

14. Levy, S., "Generalized Correlation of Bolling Heat Transfer", Journal of Heat Transfer, February 1959.

15. Aladyev, I.T., et al, "Boiling Crisis in Tubes", 1961 International Heat Transfer Conference, Boulder, Colo. (28). 


\section{REFERENCES (cont'd)}

16. Griffith, P., Clark, J.A., and W. M. Rohsenow, "Void Volumes in Subcooled Bolling Systems", ASME Paper No. 58-HT-19, 1958.

17. Maurer, G.W., "A Method of Predicting Steady State Boiling Vapor Fraction In Reactor Coolant Channels", Bettis Technical Review, WAPD-BT-19, 1960.

18. McAdams, W.H., et al, "Heat Transfer at High Rates to Water with Surface Boiling", Industrial and Engineering Chemistry, Vol. 41, 1949.

1y. Janssen, E. and J.A. Kervinen, "Burnout Iimits for Single Rod in Annular Geometry, 600 to 1400 PSIA", GEAP-3703 (in preparation).

20. Levy, S., "Prediction of Two-Phase Pressure Drop and Density Distribution from Mixing Length Theory", ASME Paper 62-HT-6.

21. Silvestri, M., "Two-Phase (Steam and Water) Flow and Heat Transfer", 1961 International Heat Transfer Conference, (39).

\section{NOMENCLATURE}

A heat transfer area, $f t^{2}$

$B$ proportionality constant, non-dimensional

C diffusion coefficient, $\mathrm{ft}^{\mathrm{k}} / \mathrm{hr}$

$c_{p}$ specific heat, BTU $/ 1 b^{6} F$

$D$ hydraulic diameter, ft.

$G$ mass flow rate per unit area, $\mathrm{lb} / \mathrm{hr}-\mathrm{ft}^{2}$

g gravitational constant, $\mathrm{ft} / \mathrm{hr}^{2},(32.2)(3600)^{2}$

$\mathrm{h}$ heat transfer coefficient, BrU/hr-ft ${ }^{2} \mathrm{O}_{\mathrm{F}}$

$\mathrm{h}_{\mathrm{fg}}$ heat of vaporization, BTU/lb

$\mathrm{K}$ mixing length constant, non-dimensional, (0.4)

$k$ thermal conductivity, BTU/hr-ft ${ }^{\circ} \mathrm{F}$

$M$ mass transfer rate, $1 \mathrm{v} / \mathrm{hr}-\mathrm{ft}^{2}$

$\mathrm{m}$ exponent, non-dimensional

$P$ pressure, psia

q heat flux, BTU/hr.

$\mathrm{T}_{\mathrm{S}}$ saturation temperature, $\mathrm{O}_{\mathrm{F}}$

$\mathrm{T}_{\mathrm{W}}$ wall temperature, OF

$x$ steam quality, non-dimensional

$y$ distance from channel wall, ft.

$\bar{\alpha}$ average vapor fraction in channel, non-dimensional

$\beta$, non-dimensional constant

$\beta_{f}^{\prime}$ value of at $\mathrm{GD} / \mu_{L}=10^{5}$

$\delta$ liquid film thickness, ft.

$\mu$ absolute viscosity, lb/hr-ft

$\rho$ density, $1 \mathrm{~b} / \mathrm{ft} 3$

$\sigma$ surface tension, $1 \mathrm{~b} / \mathrm{ft}$

$\Delta T_{\text {sub }}$

subcooling, or saturation temperature less bulk fluid temperature, ${ }^{\circ} F$ 
SUBSCRIPTS

$\begin{array}{ll}\text { a } & \text { average } \\ \text { c } & \text { conduction } \\ \text { F } & \text { forced convection } \\ \text { I liquid } \\ \text { M mass transfer } \\ \text { p pool boiling } \\ \text { v vapor }\end{array}$




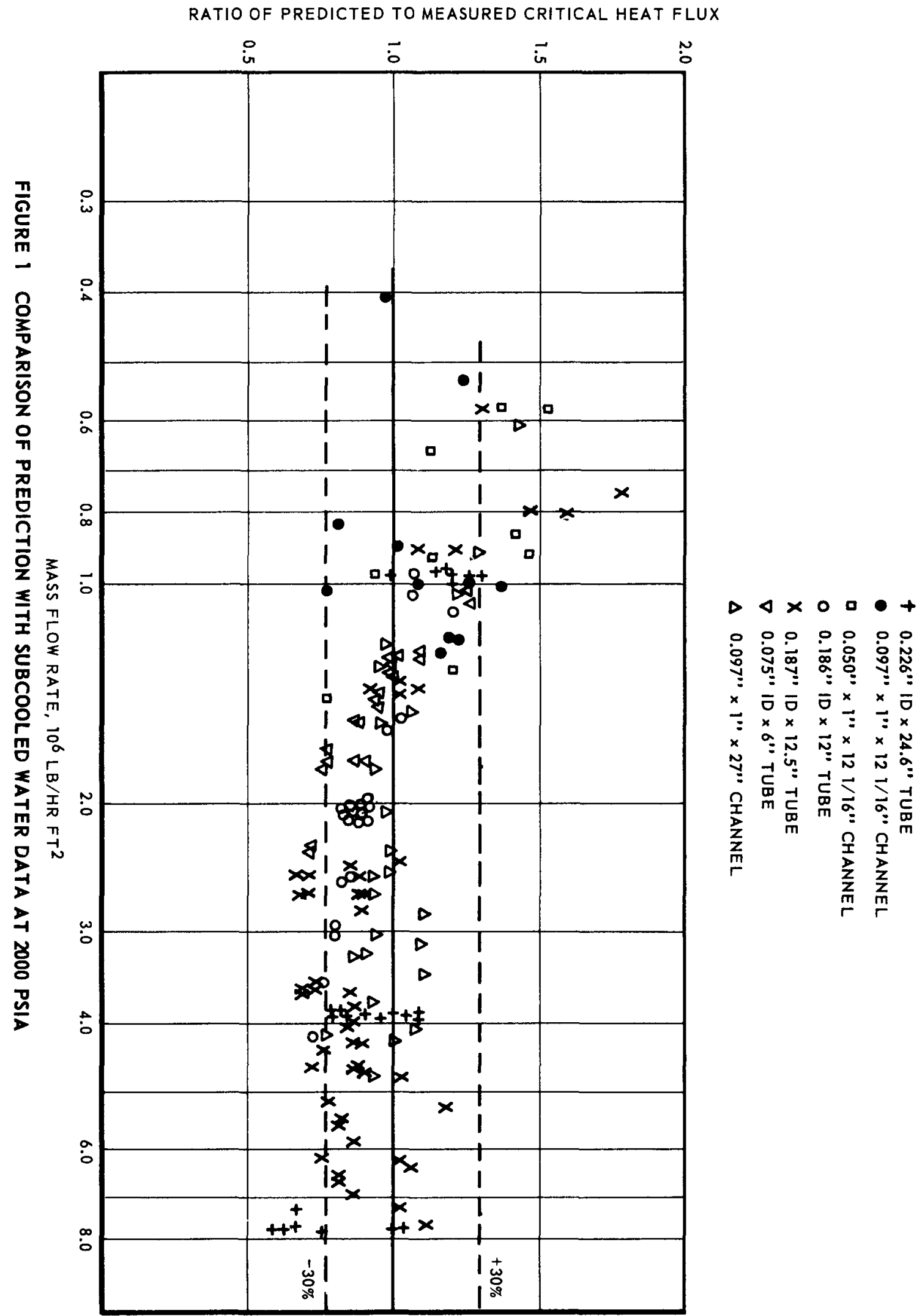


$0.050 \times 1 \times 121 / 16 \mathrm{INCH}, \mathrm{G}=0.56-0.67 \times 10^{6} \mathrm{LB} / \mathrm{HR} \mathrm{FT}^{2} 0$

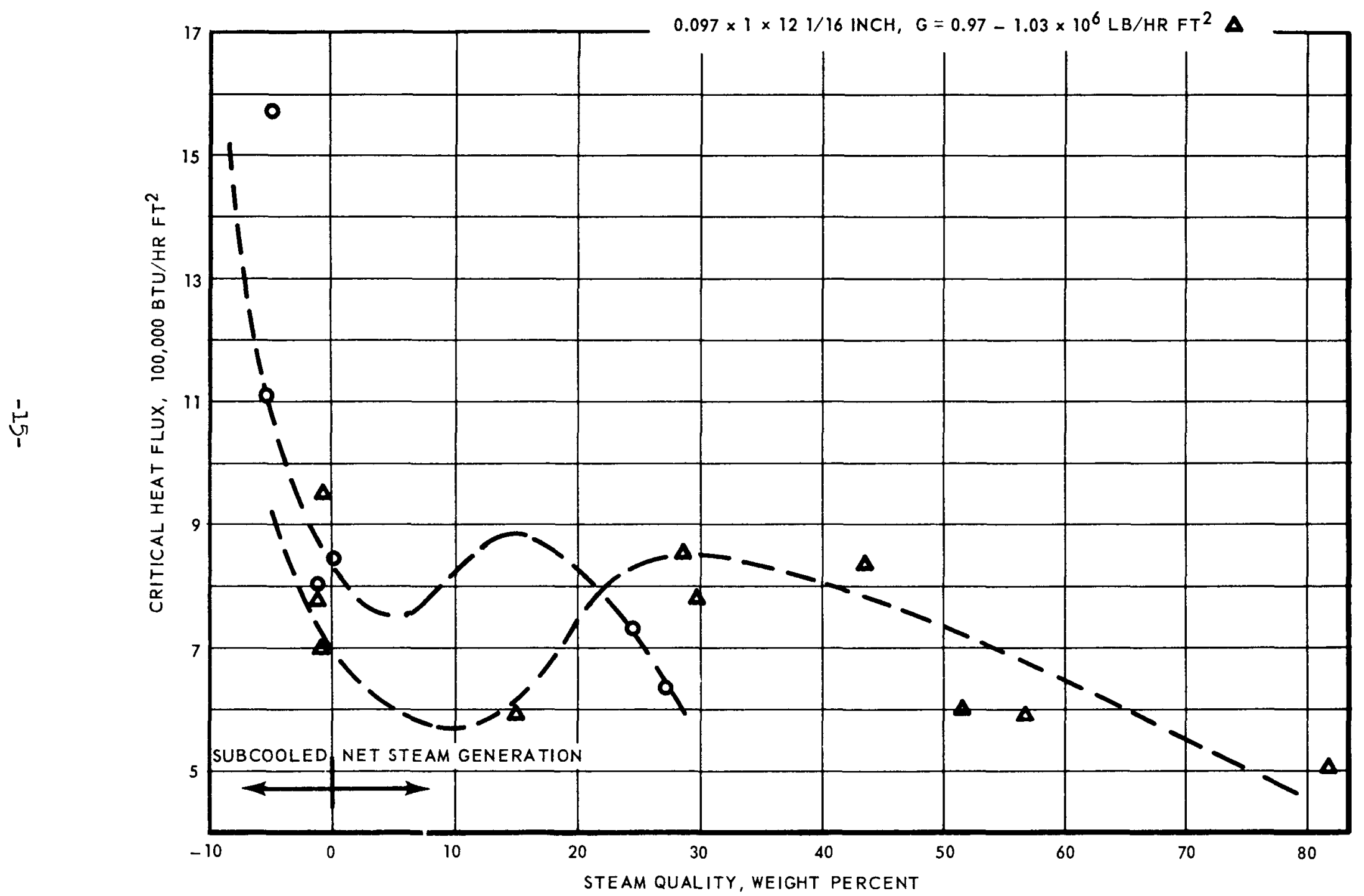

FIGURE 2 POSSIBILITY OF HYDRAULIC OSCILLATIONS AT LOW FLOWS 


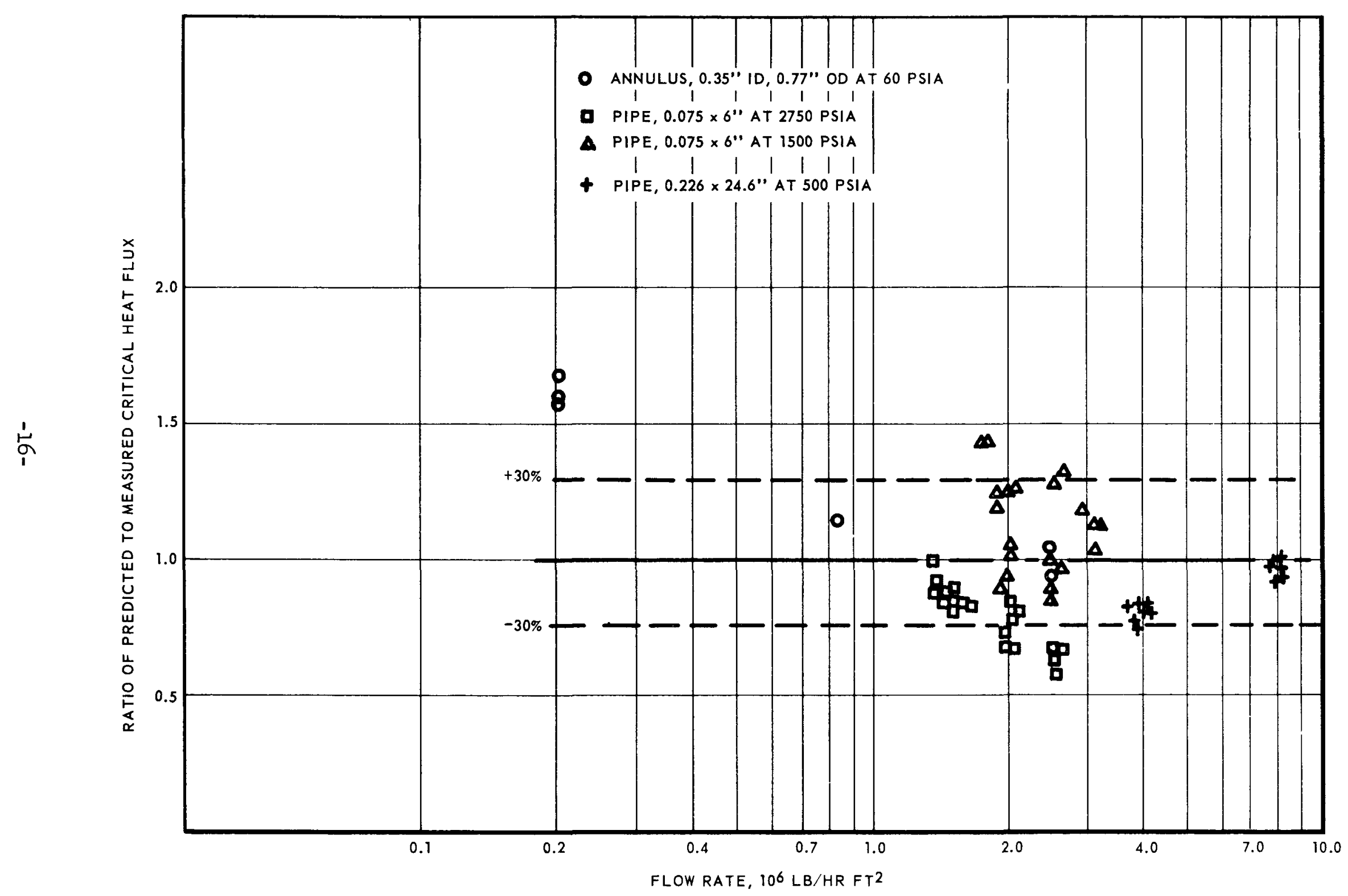

FIGURE 3 COMPARISON CF PREDICTION WITH SUBCOOLED WATER DATA AT PRESSURE OF 60-2750 PSIA 


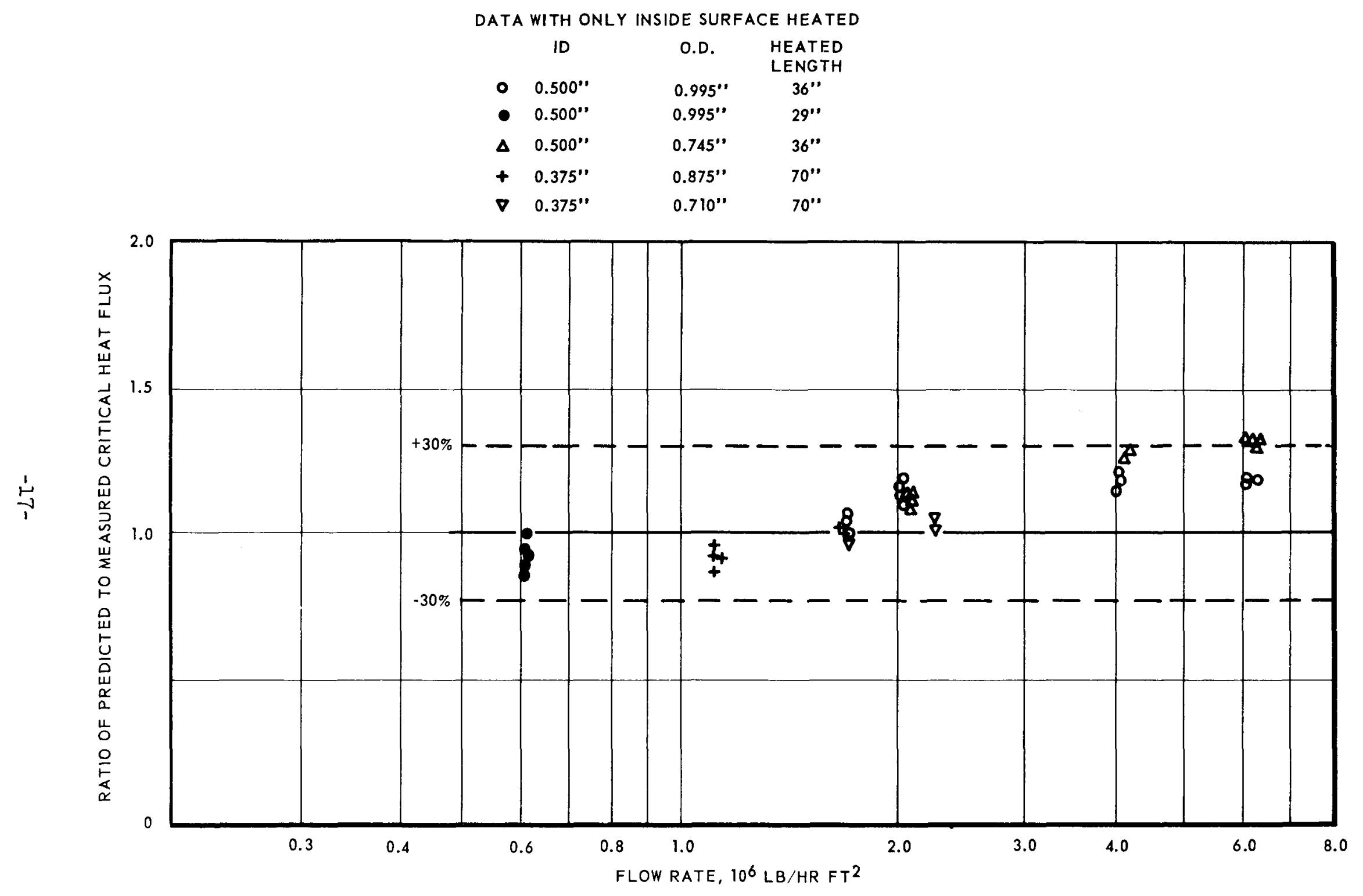

FIGURE 4 COMPARISON OF PREDICTION WITH SUBCOOLED WATER DATA IN ANNULUS AT 1000 PSIA 


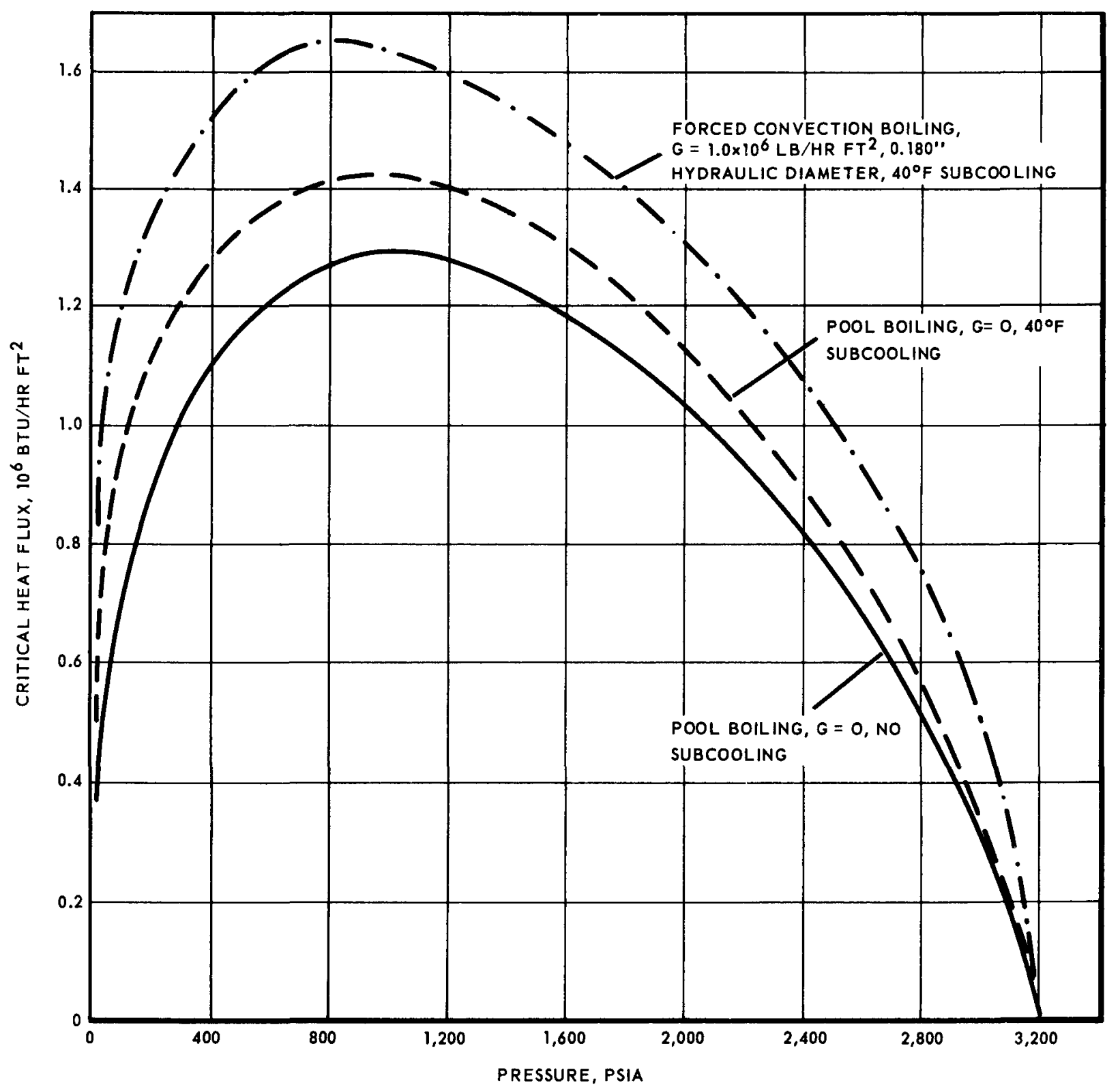

FIGURE 5 EFFECTS OF SUBCOOLING AND FORCED CONVECTION UPON CRITICAL HEAT FLUX OF WATER 


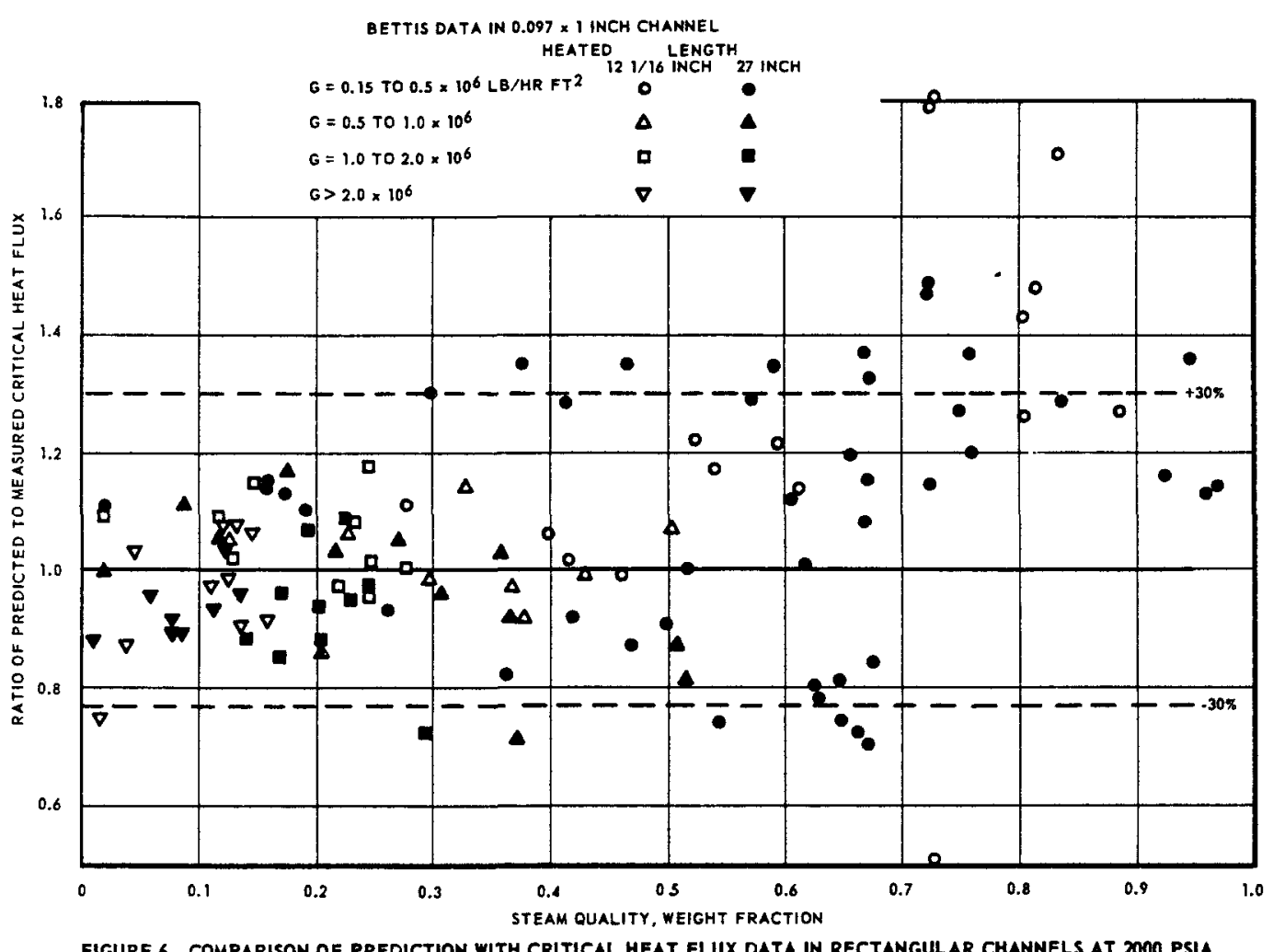

FIGURE 6 COMPARISON OF PREDICTION WITH CRITICAL HEAT FLUX DATA IN RECTANGULAR CHANNELS AT 2000 PSIA 


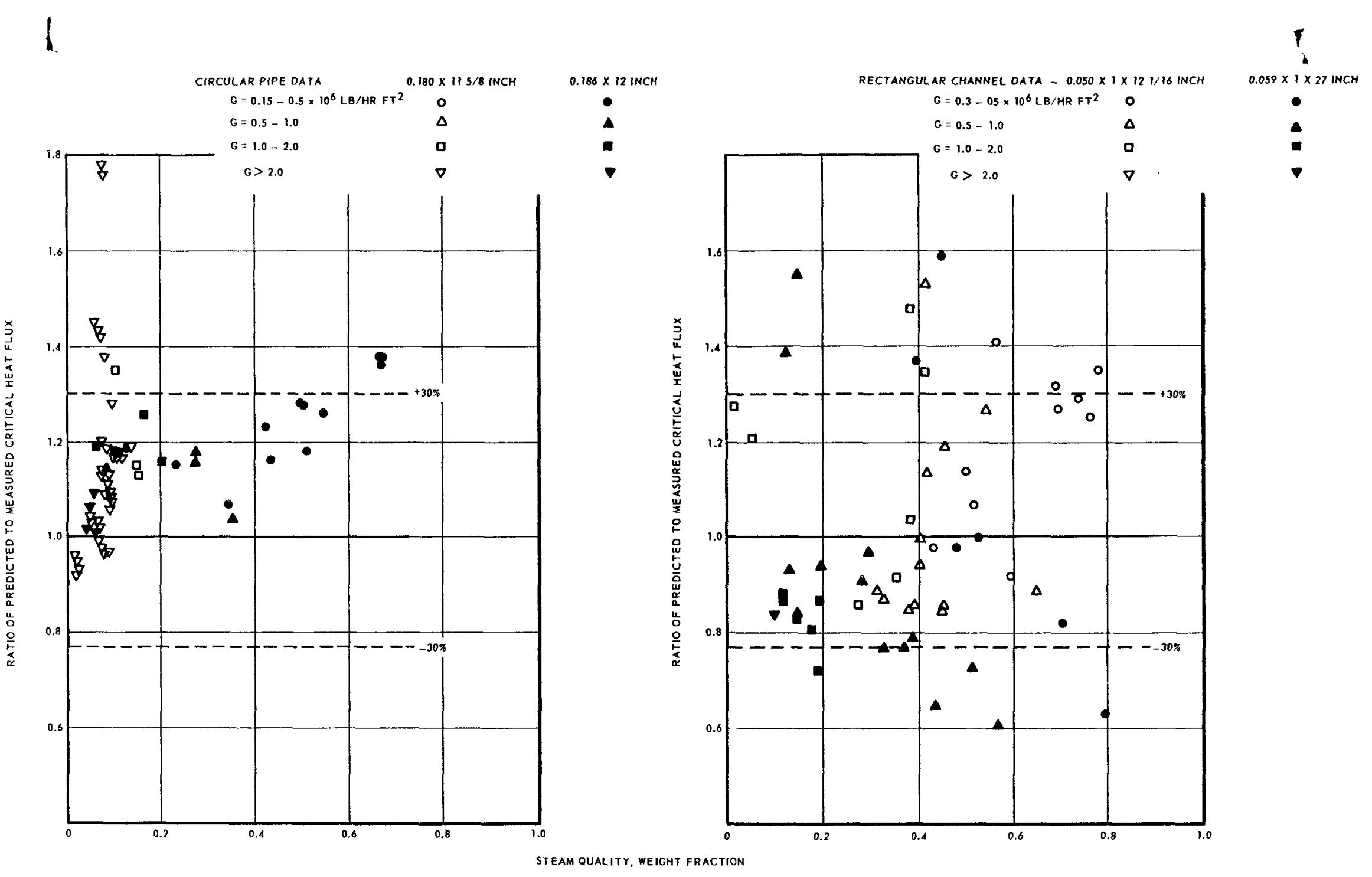

FIGURE 7 COMPARISON OF PREDICTION WITH OTHER CRITICAL HEAT FLUX DATA AT 2000 PSIA 

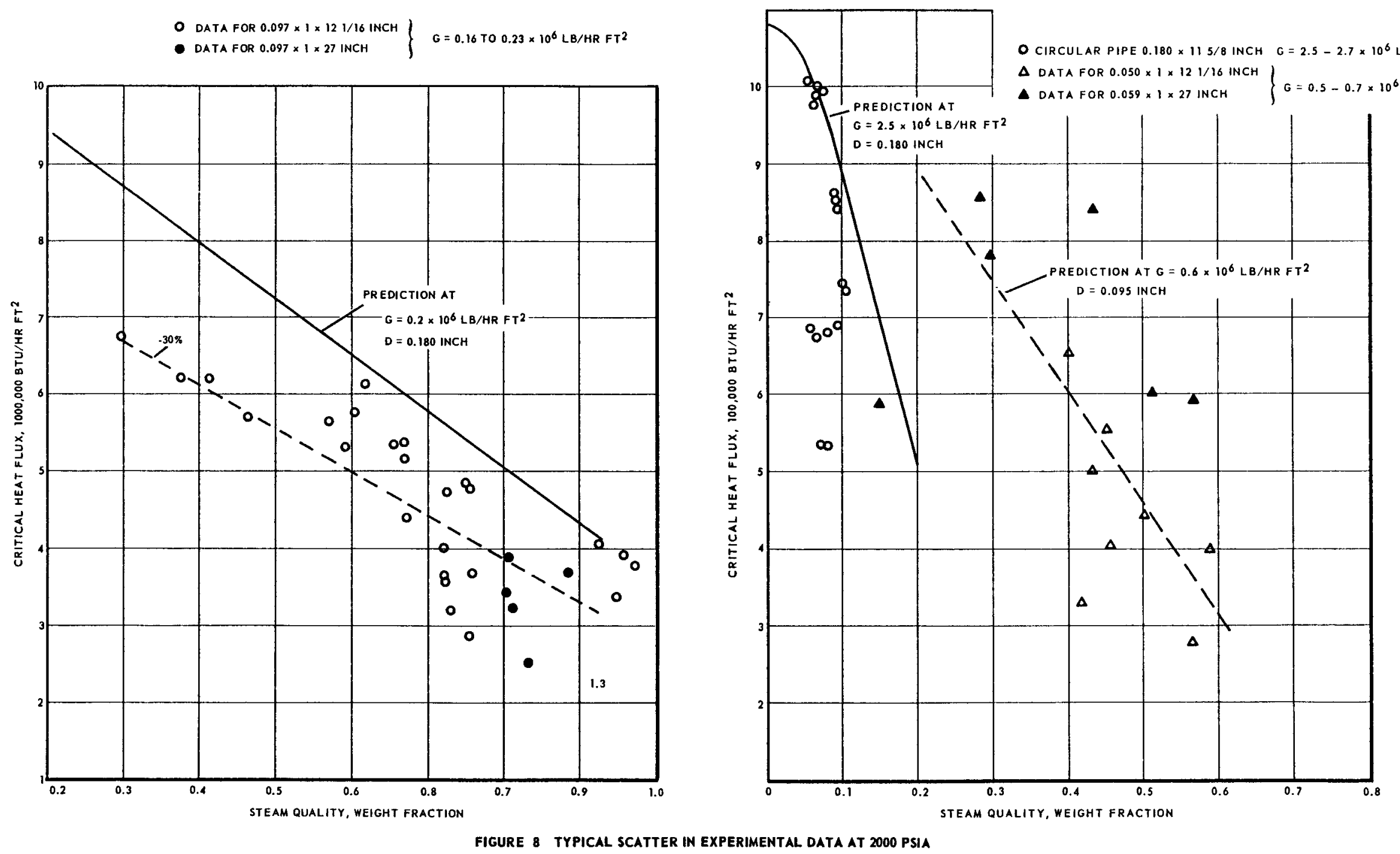


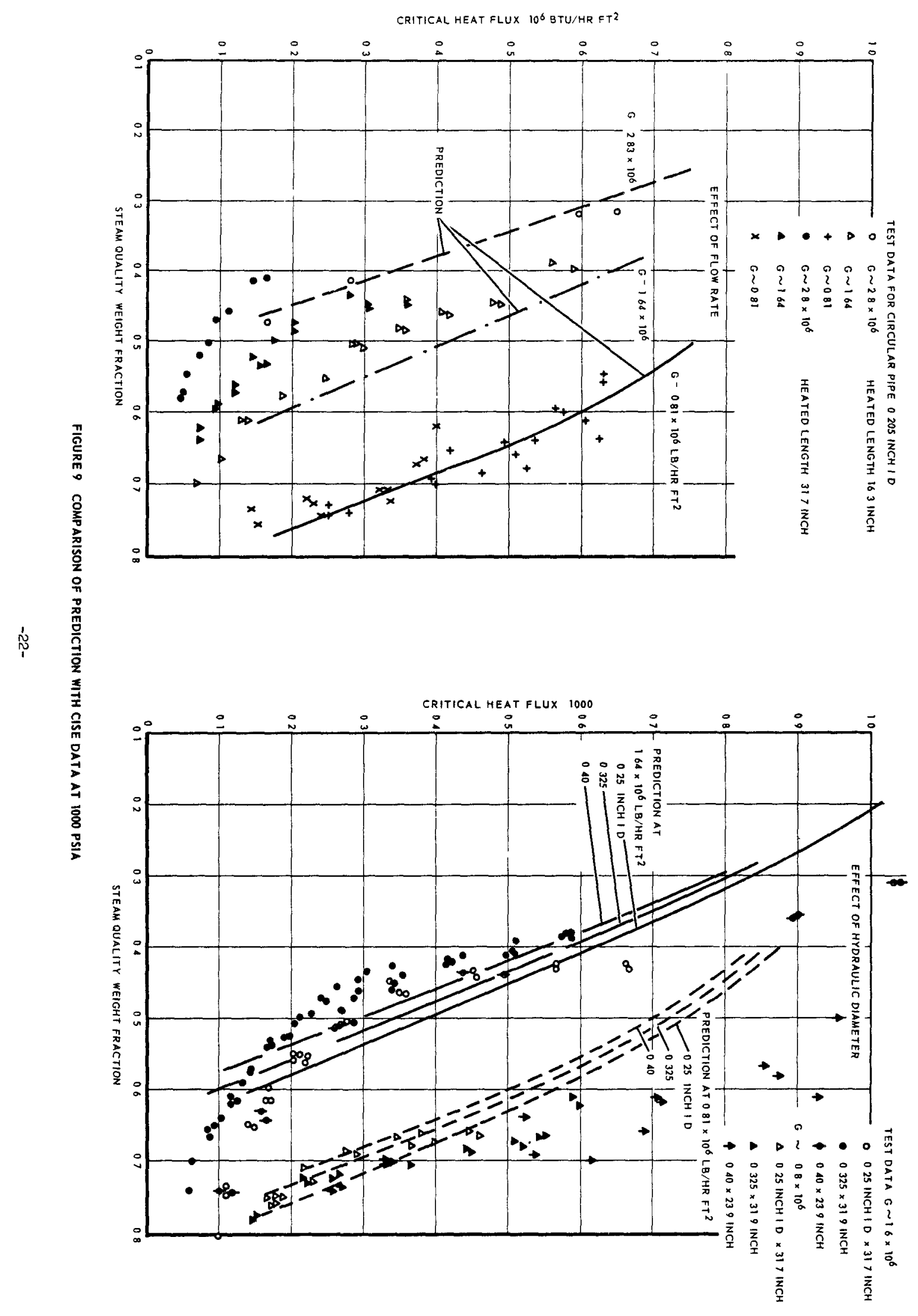




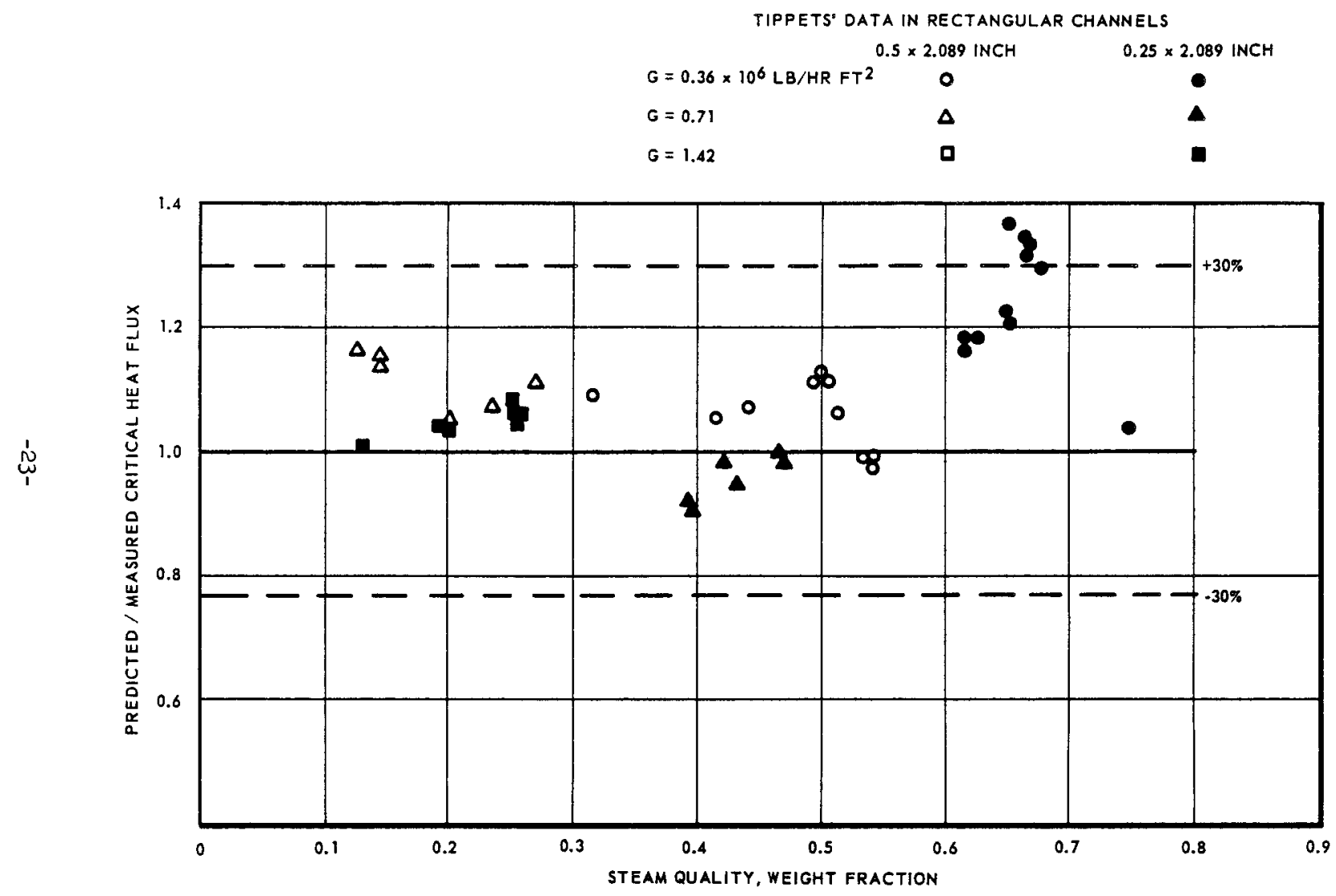

FIGURE 10 COMPARISON OF PREDICTION WITH RECTANGULAR CHANNEL DATA AT 1000 PSIA 

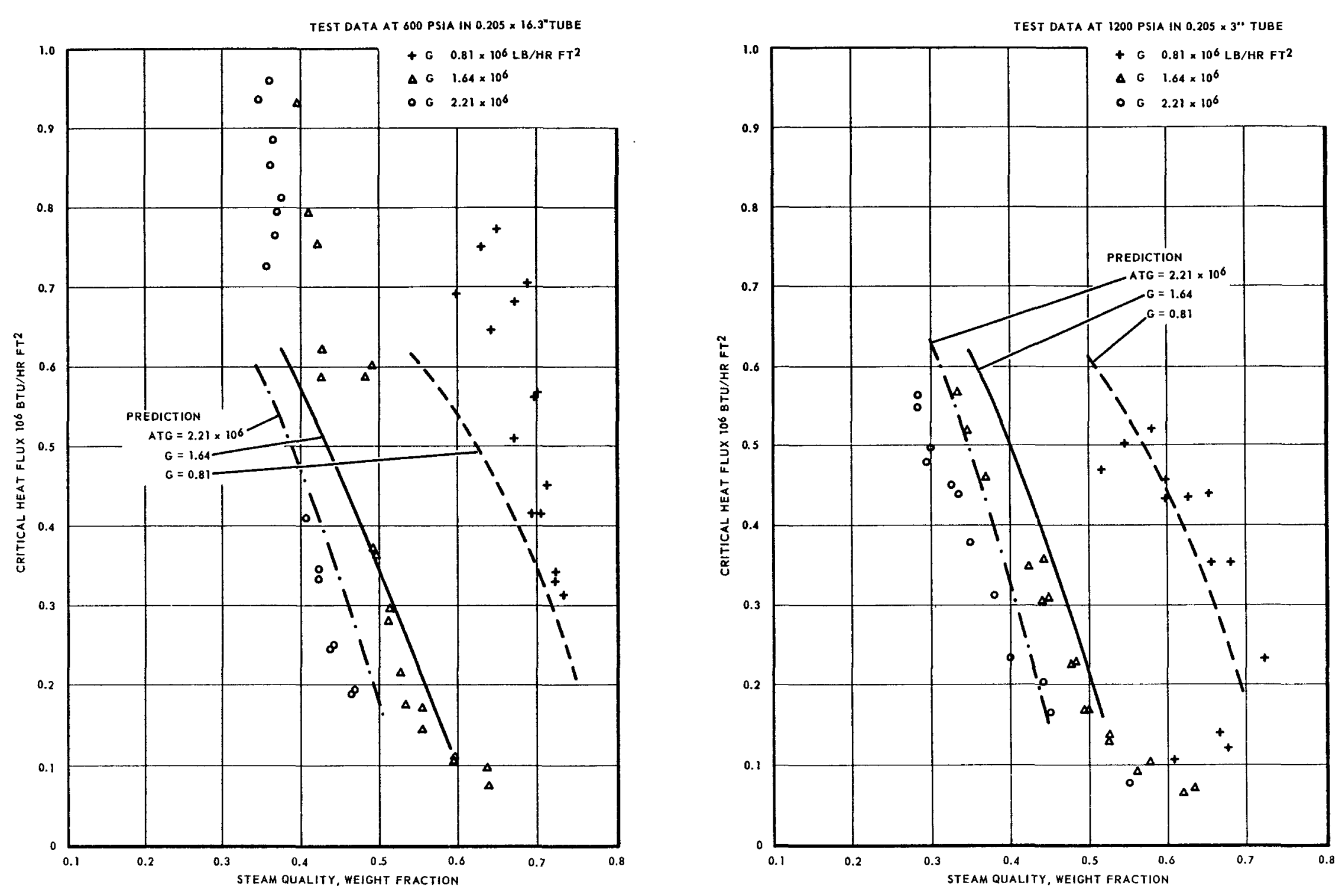

FIGURE 11 COMPARISON OF PREDICTION WITH CISE DATA AT OTHER PRESSURES 


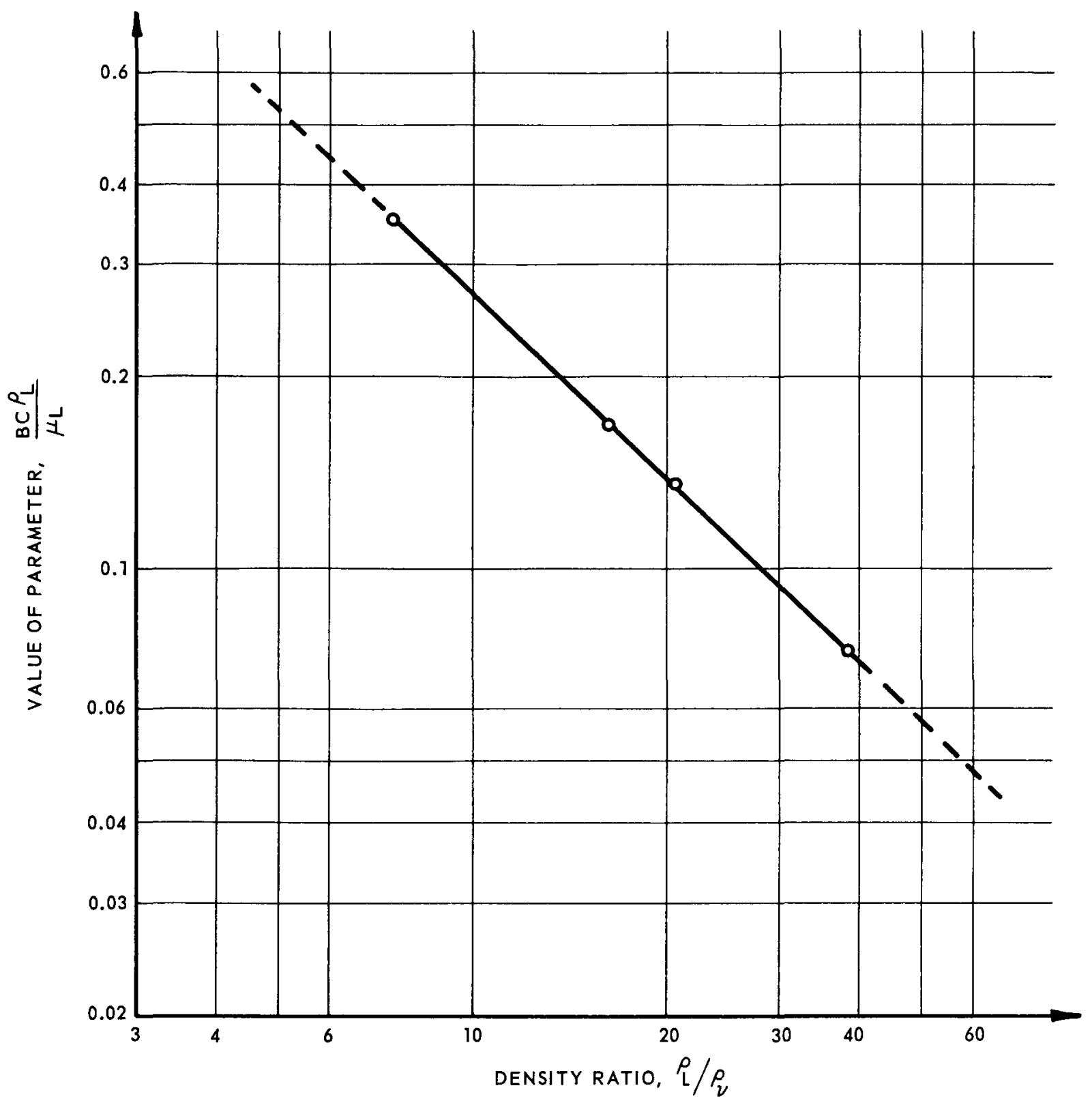

Figure 12 VALUE OF PARAMETER $\frac{B C P}{\mu_{L}}$ FOR FLOW BETWEEN PARALLEL PLATES 


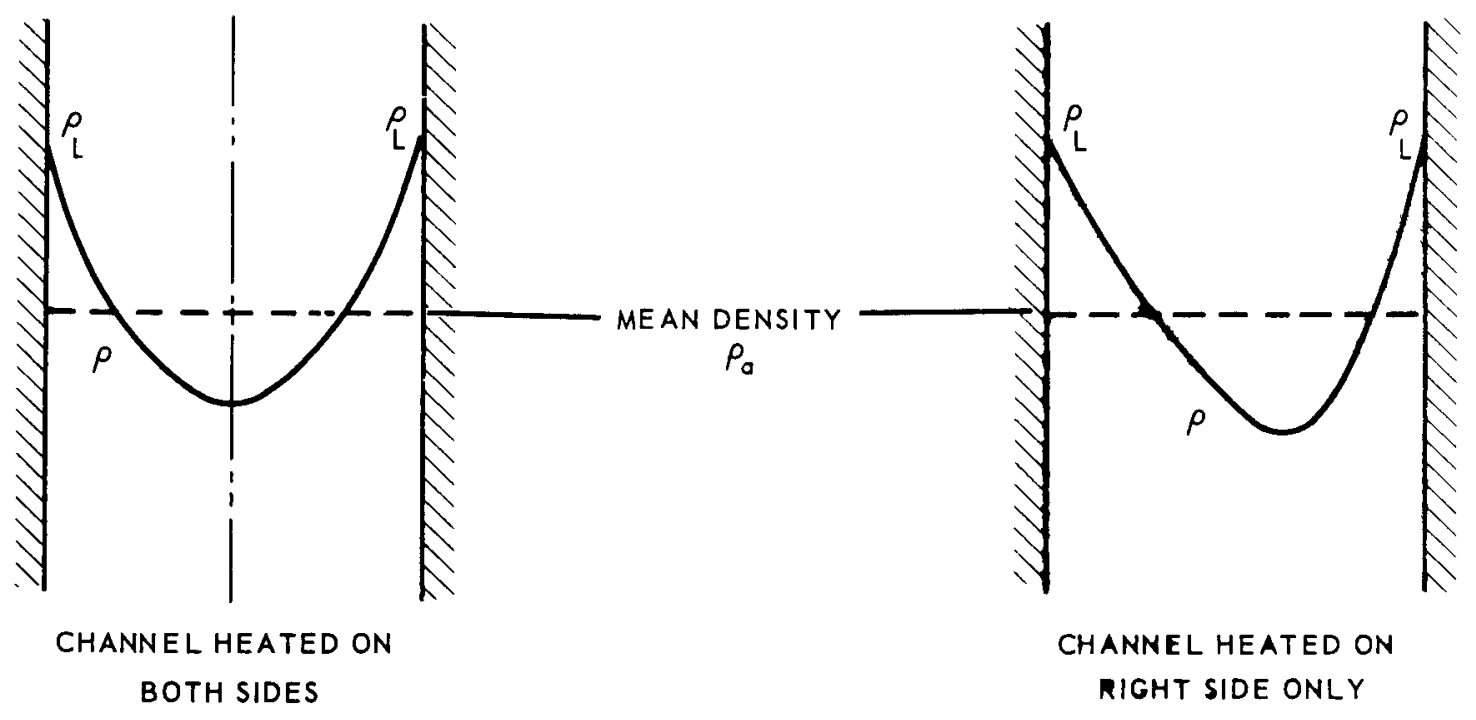

FIGURE 13 EFFECTS OF ASSYMETRIC HEATING UPON DENSITY DISTRIBUTION 

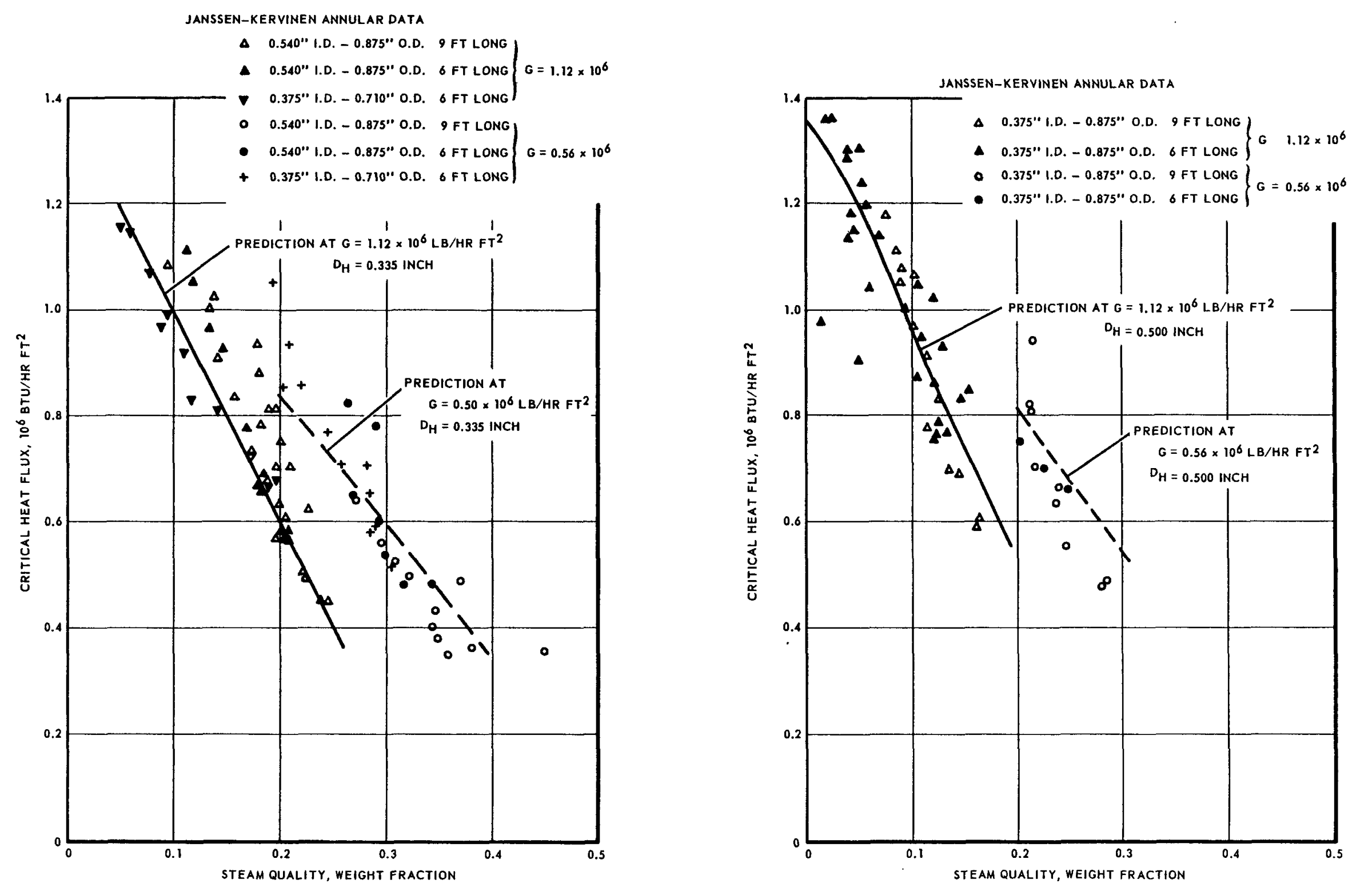

FIGURE 14 COMPARISON OF PREDICTION WITH INTERNALLY HEATED ANNULAR DATA AT 1000 PSIA 


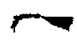

F. 